\title{
School Counselors: Key Stakeholders Helping Underserved Students to be Career Ready
}

\author{
Allison C. Paolini ${ }^{1, *}$ \\ ${ }^{1}$ Kean University, 1000 Morris Ave., Union, NJ 07083, USA \\ *Correspondence: Kean University, 1000 Morris Ave., Union, NJ 07083, USA. E-mail: paolinia@kean.edu
}

Received: April 9, 2015

Accepted: May 12, 2015 Online Published: May 14, 2015

doi:10.5430/jct.v4n1p133

URL: http://dx.doi.org/10.5430/jct.v4n1p133

\begin{abstract}
This paper addresses the role that school counselors play in assisting underserved students to be prepared for post-secondary enrollment and/or career entry upon high school graduation. Counselors' responsibilities are outlined, including assisting students in identifying their strengths and inner resources, in order to achieve their goals. Challenges that underserved students face and best counseling practices are addressed, in order to ensure that all students reach their potential and accomplish their career objectives.
\end{abstract}

Keywords: underserved students; career readiness; best counseling practices; schools

\section{National Statistics Regarding Drop-Out Rates and Retention}

Research has shown that minority students are more likely than white students to be labeled as 'at-risk' and the number of college bound African-American students has decreased significantly over the past several years (NCES, 2013). While $70 \%$ of white high school graduates entered college immediately upon graduation in 2010 , only $66 \%$ of African American students and 60\% Hispanic graduates, respectively, did the same (Aud, Johnson, Kena, Roth, Manning, Wang, \& Zhang, 2012). Moreover, the national dropout rate for students of different ethnicities in the United States is as follows: Hispanic (18.3\%), African-American (9.9\%), Caucasian (4.8\%), and American Indian/Alaskan Natives (14.6\%). Further, males are more likely than females to drop out of high school (Aud et al., 2012).

Another factor that impedes the college retention rate is that many new and underprepared college students must also enroll in remedial classes. Twenty percent of incoming freshmen at four-year institutions and fifty-two percent of students at two-year colleges are scheduled for some type of remedial coursework. Additionally, minority students such as African-American, Hispanic, and students from low-income families enroll at the highest percentages (Complete College America, 2012) in two-year colleges rather than four-year institutions. 82\% of the nation's high-achieving students from low-income households do not apply to a single school that meets their academic qualifications (The College Board, 2014). According to the Bidwell (2015) graduation rates amongst all students are higher than before and the achievement gap is slowly closing. The graduation rates for African American and Hispanic students increased by $4.2 \%$ point, where as the graduation rate for Caucasian students has only increased by 2.6\% points (Bidwell, 2015). American Indian students, students from low socio-economic statuses, limited English language proficiency students, and students with disabilities also experienced enhanced graduation rates. The achievement gap between Hispanic and Caucasian students decreased by $1.6 \%$ points and the achievement gap between African American and Caucasian students decreased by 1.1\% points (Bidwell, 2015). However, even though the nation's overall graduation rate was $81 \%$ during the $2012-2013$ school year and the achievement gap is decreasing, Caucasian students are still graduating at a much higher rate $(86.6 \%)$ in comparison to other minority groups (Bidwell, 2015).

\section{School Counselors Role: Promoting Career Readiness}

Although counselors are identified as the stakeholders responsible for ensuring that all students are career ready, there are societal factors impacting students that may be beyond the control of counselors, as well as internal 
institutional factors that need to be addressed to foster students' preparation for college and the work force. Regardless of these challenges, however, counselors are still expected to be knowledgeable about the ways and means to assist students to be career ready. In the current global economy, school counselors are key stakeholders who are responsible for preparing all students, including the underserved population, to be career ready. Gysbers \& Lapan (2009) define career ready students as, 'proactive, resilient, and having an adaptive style of interacting in the present and move towards having self-defined career futures that add meaning, purpose, and satisfaction to their lives.' Rather than being college and career ready, the word career is used, since it includes the life roles, settings, and events of individuals' lives that are constantly being influenced by such factors as gender, ethnic origin, race, spirituality, social class, and sexual orientation (Gysbers, 2013).

According to the American School Counselor Association (ASCA, 2012), school counselors are encouraged to recognize that every student possesses unique interests, abilities, and goals that can lead to a myriad of future opportunities. Therefore, aiding students in the career planning process is a paramount task that counselors are mandated to complete. These plans assist students in exploring college majors and careers that reflect their interests, passions, and strengths in order to identify the objectives that are most feasible for them to pursue.

School counselors are also required to understand the national, state, and local competencies and programs that can potentially affect opportunities for career readiness and play a pivotal role in helping students engage in academic and career planning (ASCA, 2012). Therefore, school counselors need to provide knowledge to their students and their families about the college admissions and application processes, as well as the necessary requirements for their intended careers. The challenge for school counselors, however, is to determine how to implement specific services to the underserved populations, in addition to the multitude of other required counselor tasks and responsibilities. Thus, the purpose of this paper is to identify the practical interventions to help school counselors prepare at-risk underserved populations to be career ready.

\section{Defining Underserved Populations}

According to Inver Hills Community College (2014), underserved students are those defined as students who have been traditionally excluded from full participation in our society and its institutions. The basis of exclusion has for the most part been race and color, including African Americans/Black, Asian, Hispanic, American Indian and multiracial. Underrepresented students include underserved students plus first generation and low-income students. According to Swanson (2010), 1.3 million students nationwide are not graduating with diplomas, the majority of whom are underserved students experiencing poverty and hardship. Across the country minority students and low-income students are still achieving at lower levels than more affluent and advantaged students (Hammond, Friedlaender \& Snyder, 2014). Many underserved students demonstrate feelings of isolation and estrangement in their schools leading to higher drop-out rates. Ladson-Billings (2006) found that the term 'at-risk' contributes to the challenges, as students who are labeled 'at-risk' may internalize this label and may not work to their potential or excel. Thus, it is vital for school counselors to enhance students' motivation and perspective towards school so that they are engaged and believe that they are capable of improving their academic performance rather than feeling discouraged and uninvolved.

According to Kearney \& Levine (2014) high levels of income inequality and low rates of social mobility play an integral role in the educational attainment of students in low-income homes. The researchers revealed that low-SES status students, particularly boys from low- income areas are more likely to drop out of high school. It was determined that youth from low- income areas and those who have little social mobility are more likely to have poorer educational outcomes (Kearney \& Levine, 2014). Therefore, it is imperative for counselors to work closely with students and parents to assist them in determining ways to become more academically successful in order to break the cycle of poverty and close the achievement gap (Ladson-Billings, 2006).

\section{Career Readiness: Underserved Students}

Many students, particularly students from underrepresented backgrounds, tend to rely on sources outside of the school for information on college planning. Several studies have found that parents and siblings are commonly cited as more influential than school counselors in the college planning and search process (NCES, 2013). Thus, information, advice and directions tend to be handed-down, sometimes providing students with inaccurate or outdated information. Students in schools, with high counselor caseloads, are less likely to visit the school counselor than their peers in more affluent circumstances. Yet, research shows that African-American students, female students or those students who believe the counselor has high expectations for them are more likely to visit the school 
counselor for college planning purposes (NCES, 2013). Minority students' who were asked about their satisfaction with the college counseling and preparation they received, indicated that their desired levels of support from counselors exceeded the support they received (NCES, 2013). Overall, students repeatedly report widespread dissatisfaction with their school counselors, since they feel uninformed and underprepared to manage the college application and financial-aid process or to navigate the postsecondary educational options independently. Students consistently reported needing and wanting more support. Therefore, the counselors' imperative is to dedicate more time to the college planning process in order to make it more understandable, feasible, and less over-whelming for underserved students. Active support from counselors leads underserved students to be more engaged in college planning, and more likely to both complete college applications and ultimately enroll in college (NCES, 2013).

\section{Challenges for Disabled Students}

Students with learning disabilities are those that may have sensory deficits (blindness or deafness), intellectual, orthopedic, learning, emotional, or attention deficits. There are several challenges which students with disabilities face, including needing more time to complete tasks, more time to learn and apply concepts, require teaching styles tailored to students' individual needs, may require interpreters, may need more time taking exams, and mandate more structured learning environments (American Institute for Research, 2013).

Learning disabled students lag behind the mainstream population in regards to graduation rates and post-secondary completion rates. In $2005,45.6 \%$ of youth with disabilities graduated from high school versus $62.6 \%$ of non-disabled students who graduated from high school (Newman, Wagner, Cameto, Knokey \& Shaver, 2010). According to feedback from school personnel, seventy-seven percent of students with handicapping conditions set post-secondary education as their post-high school goal (Wagner, Newman, Cameto, Levine \& Garza, 2006). However, only fifteen percent of high school graduates with disabilities attended a four-year college after leaving high school, as compared to thirty-seven percent of young adults in the general population (Sanford, Newman, Wagner, Cameto, Knokey \& Shaver, 2011). In addition, the United States will require at least 4.7 million new workers with post-secondary certificates to meet labor-market demands (Carnevale, Smith \& Strohl, 2010). A report from the Georgetown University Center on Education and the Workforce indicates that if current trends continue, by 2018 the United States will need 22 million new college degrees, but will fall short of that number by at least 3 million postsecondary degrees (i.e., Associate degree or higher). Thus, as we work to increase the number of youth who are career ready, we must ensure that students with disabilities are not left behind.

\section{Best Practices: Helping Students with Disabilities to be Career Ready}

There are several practices that educators and counselors can implement in order to ensure that learning-disabled students are career ready. One method includes ensuring that disabled students understand what career readiness means in terms of being prepared for post-secondary education without the need for remediation. Additionally, it is vital that school counselors set high expectations for this population, as doing so will challenge them to reach their full potential. It is also important for counselors to encourage them to identify their aspirations in order to achieve their goals (American Institute for Research, 2013). School personnel also need to help these students develop critical skills such as independence, self-determination, social skills, and attitudes--maturity, resilience, and self-management (American Institute for Research, 2013). Many of these students are encouraged to develop these skills by engaging in extracurricular activities, after school programs, and internships in order to have real life experiences and an opportunity to apply their newly acquired skills.

Ultimately it is also constructive for counselors to design broader accountability systems that value and measure acquisition of skills beyond academic success. Helping learning-disabled students to develop and assess multiple types of knowledge, skills, and behaviors that are important to life success are the ingredients for the $21^{\text {st }}$ century workforce. 'Soft' skills such as independence, self-determination, decision-making/problem solving, self-management, impulsivity management, leadership, intrapersonal, and interpersonal abilities need to be incorporated into the curriculum and instruction when teaching and counseling learning-disabled students (Cobb \& Alwell, 2007). Today, there appears to be a narrow focus on academic skills and standardized tests so many learning-disabled students are being measured against assessments that fail to recognize their strengths, knowledge, skills, and abilities (Center on Instruction, 2008).

Counselors especially need to help these students to set goals that reflect the students' strengths, assets, abilities, and aspirations, while encouraging them to maximize achievement based on these abilities (American Institute for Research, 2013). Moreover, counselors and educators are encouraged to use rigorous research-based instructional 
practices to foster their understanding of the unique needs, learning progressions, and supports required to help these students to succeed. Teaching the process of learning has been found to be an effective strategy to use with learning-disabled students (Center on Instruction, 2008).

Students with disabilities also need assistance in finding institutions that support students with accommodations. Counselors need to know which colleges offer support for students with learning disabilities to help students make informed decisions about their college selections. Counselors also need to develop the resources to work with this population in the college exploration process and to connect disabled students to outside college and community sources. Transition plans for these students need to address their goals, interests, and future desires and should clearly delineate how high school supports will be offered throughout the transition process (Burgstahler, Moore \& Crawford, 2011).

\section{Challenges for Hispanic Students}

The education of Hispanic students in the United States has reached a crisis stage. Even though the number of Hispanic students attending public school has increased, a gap in the graduation rate still exists. In 2013, 68.1\% of Hispanic students nationwide are graduating from high school. Out of the 50 states, Florida graduates the highest percentage of Hispanic students at 77.1\% (ACT, 2012). Although ACT scores for Hispanic students are improving, there are still major discrepancies that exist. According to the ACT (2012) Hispanic students were tested by subject and outcomes which show that $49 \%$ of Hispanic students met the Benchmark in English, in comparison to $67 \%$ of all other students; $36 \%$ of Hispanic students, met the Benchmark in Reading, in comparison to $52 \%$ of all other students; $31 \%$ of Hispanic students met the Benchmark in Mathematics, in comparison to $46 \%$ of their peers, and $16 \%$ met the Benchmark in Science, in comparison to $31 \%$ of their peers, and only $14 \%$ met the College Readiness Benchmark for all four subjects, in comparison to $25 \%$ of all of their peers (ACT, 2012).

Further, according to ACT (2014), the findings state that disaggregating data by demographic groups is vital, since at-risk minority groups are more likely to have students who are 'far off track', as well as fewer students who can catch up to the standards set at their grade level. Far off track students are defined as those who are a more than a full standard deviation below the benchmark (ACT, 2014). One of the major challenges is that these students may not be provided with academic interventions until high school, and they need to receive interventions during elementary and middle school so that they are adequately prepared for secondary schooling. Of fourth graders, $47 \%$ of Hispanic students were far off track in Mathematics, 56\% of Hispanic students were far off track in Reading, and 58\% of Hispanic students were far off track in Science. Of eighth graders, $40 \%$ of Hispanic students were far off track in Mathematics, $50 \%$ of Hispanic students were far off track in Reading, and 38\% of Hispanic students were far off track in Science. Thus, it is imperative that school counselors intervene early on to advocate for the appropriate interventions and supports necessary for these students to be prepared for the academic curricula at the secondary level. Hispanics also constitute about $75 \%$ of students enrolled in limited English proficiency (LEP) classes. English language learners (ELLs), primarily composed of Hispanic populations, face some of the most significant challenges in becoming prepared for college and careers. Conditions of poverty, health, and other social issues have made it challenging for Hispanic students to improve their educational status. They often struggle to become proficient in English while trying to meet challenging academic standards, and because they are frequently placed in mainstream classes without having language support, long-term ELLs often become disengaged in school (Olsen, 2010).

According to Padron, Waxman \& Rivera, (2002), there are three major causes as to why Hispanic students struggle more than any other population namely 1) having a lack of qualified teachers to teach LEP populations 2) inappropriate teaching practices that do not culturally or linguistically reflect students' learning styles and 3) at-risk school environments. Overall, ELLs are twice as likely as their English proficient peers to drop out of high school in the last two years when their peers are preparing to transition to post-secondary institutions. While only $5.8 \%$ of English proficient students drop out in the last two years of high school, 10.2\% of ELLs drop out in this time period (Rumberger, 2006). Moreover, only 32\% of Hispanic students enroll in college, with only $10 \%$ of these students graduating (ACT, 2012). Due to cultural factors, many Latino students rely heavily on the advice of family members when making college decisions. Research suggests that Latino students would also benefit from increased counselor support (NOSCA, 2011).

\section{Best Practices: Helping Hispanic Students to Be Career Ready}

Overcoming a language barrier is a vital part of helping Hispanic students to succeed academically. English to Speakers of Other Languages (ESOL) is a state-funded instructional program for English Learners (ELs) in grades 
K-12 (REACHES, 2014). To supplement language services, the Title III program provides districts with additional federal funding for ESOL. Georgia uses this instructional program with many of its Hispanic students to ensure that they are prepared for post-secondary endeavors. Teachers must focus on language acquisition, the effect of culture and its impact on learning, emphasize cultural responsiveness, and use technology to support and assist English Language Learners to understand and master the English language (REACHES, 2014).

Another way to enhance academic performance amongst Hispanic students is to encourage them to participate in extra-curricular activities. Research has demonstrated that when students are involved in extra-curricular activities they are more engaged in school, have fewer absences, have better grades, and build more positive social networks (REACHES, 2014).

Cooperative learning has also proven to be an effective strategy when working with Hispanic students. Cooperative learning uses small groups in which students have specific roles in order to accomplish specific tasks and activities. This enables students to work together to maximize and stimulate their own learning as well as that of others in the group. Through collaboration, students can enhance their social skills and inter-group relations necessary for academic success. Cooperative learning has also shown to improve individual and group relationships by teaching students to clarify, assist, and challenge others' ideas; increase proficiency in English by providing students with a variety of language experiences that include speaking, listening, reading, and writing (Padron et al., 2002).

Using culturally responsive instruction has been shown to accelerate academic performance through student engagement (Charles, 2015). Teachers and counselors who are aware and open to different world views, build on students' life experiences whatever the curriculum, and create a safe and welcoming environment will foster student involvement.

According to Zalaquett (2004), meeting with parents and family members on a regular basis to address students' academic progress was found to be very effective in helping to enhance career readiness as family members play an integral role in improving attitudes towards school, as well as motivating students to succeed. Counselors are also encouraged to collaborate with teachers so that they can discuss any struggles that students may be encountering and intervene early on to ensure academic success.

Further, conducting small counseling groups that highlight topics of assertiveness, building social skills, time management, and stress management have also been found to be effective as doing so will help students to cope with the challenges that exist within the application process and the work force (Zalaquett, 2004).

Moreover, having bi-lingual college representatives is imperative so that Spanish speaking parents are made aware of the financial aid process, scholarships and grants available, as well as what the admissions process entails. Additionally, counselors and educators who develop and utilize culturally sensitive pedagogy that celebrates students' language, diversity, culture, and experiences into the school have students who are more successful and engaged (Zalaquett, 2004).

Furthermore, counselors need to work with teachers and emphasize the importance of teaching content rich curriculums in the early grades to ensure that students learn necessary vocabulary early on so that they can thrive in middle and high school. Having content rich curriculums in English, math, Science, and History helps to prepare students for their long-term education and work to close the achievement gap (ACT, 2014).

Counselors are also encouraged to conduct a gap analysis of the school's current practices to assess curriculum and academic goals, staff selection, leadership and capacity building, instructional tools, programs and strategies, monitor performance and progress, and evaluate current interventions and necessary modifications (ACT, 2014). Monitoring engagement, as well as interventions is critical so that schools are aware of areas of program strengths and deficits.

Demonstrating accountability is also essential and counselors need to document their services to show that their provisions are positively impacting this target population. In addition, counselors need to use data on underserved students' prior achievement in planning and evaluating secondary school programs. By reviewing data earlier on, students can be identified to encourage enrollment in more rigorous courses such as Advanced Placement classes. Counselors also need to determine which type of students specific programs benefit. This information is vital so that counseling services in the earlier grades can promote the effective interventions that will enable students to profit from challenging academic programs in middle and high school (ACT, 2014). 


\section{Challenges for African-American Students}

There are several environmental factors that may negatively impact the academic success of African-American students, including poverty, racial segregation, and unequal access to quality schools.

In March 2010, the Elementary and Secondary Education Act was modified to state that, 'Every student should graduate from high school ready for college and a career, regardless of their income, race, ethnic, or language background, or disability status (U.S. Department of Education, 2010). As a result of these changes, programming for career readiness has been a central focus, as well as having state wide common core standards, in order to assist all students to be college and career ready. However, despite these efforts, inequality in the education system still exists (Hogrebe \& Tate, 2010).

Another challenge is the ambiguity over the meaning and measurement of national readiness benchmarks (Camara \& Quenemoen, 2012). Even though historically GPA and standardized test scores have been used to determine a student's level of readiness, these measures have been criticized, due to their limited predictive value in regards to determining postsecondary academic success (Maruyama, 2012). In order to truly help underserved students, a deeper understanding of how context and socio-structural forces contribute to lower test scores and fewer opportunities for underserved groups to demonstrate career readiness is needed (Castro, 2012).

Structural racism and poverty need to be taken into account in order to understand differences amongst students regarding career readiness. According to the Center for American Progress (Spatig-Amerikaner, 2012), K-12 schools are just as segregated today as they were in the 1960's. Approximately 40\% of African American and Hispanic students attend schools in which over $90 \%$ of the students are not Caucasian, compared to the Caucasian student who attends schools where at least $77 \%$ of the other students are also Caucasian, which further validates racial segregation. The Center for American Progress also reports that in addition to segregation there are also discriminatory spending practices. Schools with $90 \%$ or more of minority students spend $\$ 733$ yearly less per student than schools with $90 \%$ or more of Caucasian students (Spatig-Amerikaner, 2012). Schools spend approximately $\$ 344$ more a year on white students than minority students (Spatig-Amerikaner, 2012).

Additionally, poverty rates are highly disproportionate for minority cultures in comparison to Caucasians. According to the 2010 Census, 46.2 million people in the United States live below the federal poverty level. $27.4 \%$ of African-Americans and $26.6 \%$ of Hispanics live below the poverty level, in comparison to only $13 \%$ of Caucasians. Furthermore, the rates of people who are incar-cerated are overwhelmingly minority populations (U.S. Department of Justice, 2011). Research has shown that incarceration is strongly related to educational attainment (Western \& Pettit, 2010). Thus, minority populations are at a major disadvantage in comparison to their Caucasian counter-parts, in regards to educational attainment and opportunities, due to high rates of poverty and incarceration.

Moreover, African-American students have lower ACT scores than Hispanic and Caucasian students. Obstacles such as segregated schools, unequal funding, as well as poverty have a tremendous impact on career readiness. Of the total population of students who took the ACT in 2011, benchmarks were met by at least $50 \%$ of Asian and Caucasian students, whereas none of the benchmarks were met by at least $50 \%$ of African American students (ACT, 2011). In 2012, only $36 \%$ of African American students met the English subject benchmark, in comparison to $67 \%$ of all other students, $15 \%$ of African American students met the Mathematics subject benchmark in comparison to $46 \%$ of all other students, $22 \%$ of African American students met the Reading subject benchmark, in comparison to $52 \%$ of all other students, and only $7 \%$ of African American students met the Science subject benchmark in comparison to $31 \%$ of all other students. Therefore, there is a large discrepancy in scores between ethnicities, in regards to percentages of those students who meet the standard benchmarks for each subject (ACT, 2012).

According to the NEA, $42 \%$ of African American students attend schools that are under-resourced and performing poorly and African American boys are 2.5 times less likely to be enrolled in gifted and talented programs, even if their achievement reflects their ability to succeed. (NEA, 2011). More disturbingly, less than half of African American males graduate from high school on time and are three times more likely to be suspended or expelled in comparison to their Caucasian peers (NEA, 2011).

Additionally, many African-American youth do not relate to the curriculum or teaching style of the teacher, and therefore are not engaged in class (Butler, 2003). Many teachers encourage individual work and achievement, whereas African-Americans believe in working collaboratively and cooperatively in order to better the group as a whole. Therefore, if a teacher's style of teaching is incongruent with a student's cultural beliefs, then that student may struggle to become engaged in the learning process.

Further, African-American students account for $14.6 \%$ of the public high school population, yet only represent $8.6 \%$ 
of AP exam test takers. Although counselors may stress the importance for all students to take Advanced Placement classes and exams, only 3.9\% of successful examinees (defined as scoring a 3 or above on the AP exam) are African-American (Chau, 2012). Regardless of these obstacles, school counselors still need to be motivated to create programs that help students to acquire a strong knowledge base, skills, identity, and enhanced self-worth that will lead them to be career ready.

\section{Best Practices: Helping African American Students to Be Career Ready}

Counselors must be culturally competent when working with at-risk African-American youth. Possessing an understanding of the historical background, culture, and norms, allows counselors to work more effectively with this group of students (Lee \& Wagner, 2007). Counselors are encouraged to attend cultural trainings, events, collaborate with faculty, and conduct research in order to learn more about these students' backgrounds to better meet their needs. Having a high degree of cultural awareness is pivotal for school counselors in regards to their ability to build strong and open relationships with these students and their families.

Moreover, school leadership is a critical component in helping this population to succeed. Having positive role models who embrace, celebrate, and advocate for education, as well as work to form personal relationships with students have been shown to elicit positive outcomes for students (NEA, 2011). Further, counselors who facilitate groups discussing male empowerment, addressing the importance of leadership, positivity, resilience, and overcoming adversity has been shown to be effective in enhancing graduation rates and increasing school engagement (NEA, 2011). In addition, counselors can help to create culturally responsive schools through encouraging educators to not focus on the achievement gap. Instead, counselors can work with teachers on helping students to learn material, believe in themselves and enhance self-efficacy, formulate strong relationships, encourage opportunity, and teach curricula that is relevant and applicable rather than intangible (NEA, 2011). Validating students' cultural identity, acknowledging differences and commonalities, promoting equity and respect, motivating students to take an active role in the learning process, encouraging students to think critically, and challenging students to strive for excellence has also shown to help improve career readiness amongst African American students (NEA, 2011).

Additionally, using test scores as a determining factor as to whether or not students are career ready needs to be examined. In 2004, Achieving the Dream was organized and it is to date the most comprehensive non-governmental reform movement formed to help close the achievement gap and foster success amongst minority students (Achieving the Dream, 2015). The organization was formed to help lower income community college students recognize economic opportunity and to encourage them to achieve their dreams.

Furthermore, school counselors need to help African American underserved students recognize that postsecondary schooling is an option, regardless of test scores, and to not allow low test scores to deter or discourage them from applying to college or furthering their education.

Additionally, student enrollment in remedial courses also impacts their attendance in college, as they are paying for these classes, but are not earning college credits. Thus, these students need to be properly trained and prepared in high school to develop the skills needed to successfully pass their placement tests and be ready for college level work.

Moreover, more partnerships need to be developed between universities and schools to raise awareness about higher education opportunities and to increase expectations about university attendance and success amongst students of color, their parents, and their teachers (Casto, 2007). Universities need to take a holistic approach when reaching out to these students, educate them about the college admissions process and college culture, help them to envision themselves attending a higher education institution, and work towards helping students to recognize that they should not allow environmental factors to prevent them from attending college.

Although family factors and poverty can deeply affect student performance, research has consistently shown that school counselors have a significant impact on students' access to educational opportunities, particularly post-secondary opportunities (Perna, Rowan-Kenyon, Thomas, Bell, Anderson \& Li, 2008). School counselors, especially those working at urban schools, need to have a more rigorous focus on accountability in that they must collect and analyze data on a given population in order to determine inequities and take steps to address deficits and barriers before they become epidemics (Holcomb-McCoy \& Mitchell, 2005).

Advocating for this population is also critical to their success. Lee (2005) found that schools who were more responsive to African-American at-risk students, set higher expectations, higher standards, created more challenging 
curriculums, were abreast to needs of diverse populations, forged a sense of community in the school, and were knowledgeable about how to appropriately deal with racism and racial tensions helped students to feel supported.

Lastly, counselors need to teach this population about the importance of resilience. Resilience is defined as an individual's positive response to situations of stress and adversity (Hawkins and Mulkey, 2005). Counselors can help students to instill and build resilience through encouraging parental involvement, positive peer relationships, school or team involvement, and help students to set goals towards achieving a lucrative future. Somers, Owens \& Piliawsky (2008) investigated the individual and social factors related to African American students' school performance, and determined that parental, teacher, and peer relationships played vital roles in accomplishing academic progress (Somers, et.al, 2008). Additionally, as students transitioned to a high school setting, parent, teacher, and peer support were found to be most valuable when completing school and pursuing further post-secondary schooling, educational commitment, and the work force were concerned. Therefore, counselors who help African American students to build positive family and peer networks enable students' career readiness.

\section{College Board's 4 or More Campaign: Helping At-Risk Students to More Effectively Pursue Post-Secondary Goals}

The College Board (2014) has implemented a new initiative for school counselors to assist high-achieving underserved students who score at the $75^{\text {th }}$ percentile and above and are financially disadvantaged, according to Title 1 standards, entitled 'Apply to 4 or More.' The purpose of the program is to inform these students that college is a reasonable choice, which will be beneficial over their lifetimes so that students from low-income areas will be career ready and ensure that all students, regardless of ethnicity or socio-economic status, have equal opportunities to attend college. Thus, underserved students are to be provided with information regarding college options, the college application and admissions process, as well as to encourage college attendance in order to improve graduation rates (College Board, 2014). The College Board has set specific criteria in order to mitigate barriers that hinder students from applying to colleges that are in sync with their strengths and attributes so that they can meet and exceed their potential.

According to the College Board (2014), $82 \%$ of the nation's high achieving students from low-income households do not apply to schools that meet their qualifications, thus, many of these high achieving students are underestimating their abilities, lack confidence, and or lack knowledge about the college admissions process. As a result, they are applying to safety schools rather than to more challenging institutions that could better meet their needs. School counselors can utilize this information to help low-income students be more cognizant of their opportunities for college and encourage them to apply to four or more colleges that matches their academic potential. The College Board (2014) determined that students, who apply to two colleges instead of one, are $40 \%$ more likely to enroll in a four-year school versus a two-year school. Additionally, applying to more than two colleges makes the likelihood of their enrolling in a four-year school even higher. Having a student apply to several schools, rather than being limited to only one school, enhances the chances of acceptance to a more rigorous university, resulting in a more fulfilling college experience.

\section{Discussion}

This manuscript highlights the importance for school counselors to act as change agents, leaders, and advocates in order to ensure that all students are academically successful and career ready. The article addresses the importance for counselors to help underserved students overcome barriers that they are facing via implementing best practices that have shown to elicit positive outcomes for these students. It is imperative for counselors to believe in, challenge, and educate underserved students and reinforce that anything is possible to achieve through hard work, perseverance, and diligence. Through fostering family involvement, collaborating with teachers and encouraging differential learning instruction, addressing topics that are relevant and relatable, encouraging involvement in extra-curricular activities and cooperative learning have shown to be integral techniques that counselors can use in order to enhancing career readiness. By educating and exposing students to available resources for college and careers, counselors can help to ensure that students regardless of background or socio-economic status recognize that they have the ability, confidence, knowledge, and capacity to achieve their goals.

\section{Suggestions for Future Research}

There are several suggestions for future research. Although research has shown that cooperative learning and 
involvement in extracurricular activities has shown to enhance academic success amongst underserved students (NEA, 2011), the literature fails to provide examples of how cooperative learning has effectively been implemented nor does it stipulate which extracurricular activities are most valuable to be involved in. Thus, in the future it would be advantageous for researchers to provide an example of how cooperative learning can be integrated into classroom curriculums, as well as determine which extra curricular activities have been shown to have the most positive impact on career readiness. Additionally, it would be beneficial for future researchers to determine whether or not entrance exams and test scores are indicative of student performance. Further, it would be helpful if research is conducted on the concept of resiliency and how this entity impacts academic and career success. Lastly, it would be beneficial for future research to examine the impact that enrollment in remedial courses has on student graduation and student engagement.

\section{Conclusion}

Although school counselors have made strides in recent years in regards to helping all students to succeed, there is more work to be done, as an achievement gap still exists between majority and minority cultures. In order to further close the achievement gap, counselors must create a secure school environment so that students feel safe, protected, accepted and are actively engaged in the learning process. Through implementing challenging, relevant, and rigorous curricula, students will be able to recognize a connection between what they are learning in the classroom and how they can apply knowledge attained to the real world setting, further captivating their attention and motivating them to excel. There is a need for counselors to emphasize the importance of increased parental involvement, as doing so has shown to ensure consistency between home and school, as well as shown to inspire students to succeed personally and professionally as they feel more supported. Due to the fact that learning is not universal and students have a variety of learning styles, it is paramount that counselors encourage educators to use differential instruction and techniques to ensure that all students learn material from various strategies and viewpoints, as this will help them to have a better conceptualization of the material and enable them to apply information learned. In the $21^{\text {st }}$ century, fusing in technology is imminent, as it allows students to become more technologically savvy, as well as captivates the students' attention due to its omnipresence in this technologically driven culture. Technology plays an integral role in today's society due to its immediacy, therefore, integrating technology into learning such as using Prezi, YouTube, the Internet, and Google Drive, helps to make learning more relatable, significant, and interactive, as information is accessible, exchanged immediately, and allows students to navigate their learning process. Utilizing researched based practices are essential as they have shown to elicit positive outcomes in students. As counselors are data driven practitioners; they must use what has proved to be successful, in order to ensure that all students strengthen their academic behaviors. Ultimately counselors are change agents, leaders, and advocates. Counselors are cheerleaders who must be solution focused and help underserved students to identify their strengths and assets while encouraging students to utilize their talents and inner resources in order to set and achieve SMART goals.

It is also imminent for counselors to provide insight and in-depth information about post-secondary opportunities, as many underserved students are first generation college students and may lack the knowledge about available college planning and financial aid resources, including grants, scholarships and loans that can assist them in the college admissions and applications processes and the knowledge that college can be an affordable option. Thus, it is the counselor's job to enlighten and educate students and their families to inspire them to pursue a post-secondary institution, helping them to realize their potential while making their dreams become a reality. It is vital for counselors to support students to work to their potential, as doing so will help to instill confidence, reaffirm their belief in themselves, enable students to self-actualize, and celebrate their acquired assets. Using these practices will help to ensure that all students are knowledgeable, motivated, and prepared to enter a globally competitive job market, which offers the promise of fulfilling career opportunities.

\section{References}

Achieving the Dream. (2015). Helping more community college students succeed. Retrieved from http://achievingthedream.org

ACT (2014). Catching Up to College and Career Readiness: The Challenge is Greater for At- Risk Students. Retrieved from http://www.act.org/research/policymakers/pdf/CatchingUp-Part3.pdf

ACT. (2011). The Condition of College and Career Readiness. Retrieved from http://www.act.org/research/policymakers/cccr11/pdf/ConditionofCollegeandCareerReadiness2011.pdf 
ACT. (2012). African American Students: The Condition of College and Career Readiness. Retrieved from http://www.act.org/newsroom/data/2012/states/pdf/AfricanAmerican.pdf

American Institute for Research. (2013). Improving college and career readiness for students with disabilities. Retrieved from https://disability.workforce3one.org/command/view.aspx?look=2001313651988087652\&mode=info\&pparams $=$

American School Counselor Association. (2012). The ASCA national model: A framework for school counseling programs $\left(3^{\text {rd }}\right.$ ed.). Alexandria, VA: Author.

Aud, S., Hussar, W., Johnson, F., Kena, G., Roth, E., Manning, E., Wang, X., \& Zhang, J. (2012). The Condition of Education 2012 (NCES 2012-045). U.S. Department of Education, National Center for Education Statistics. Washington, DC.

Bidwell, A. (2015). Racial gaps in high school graduation rates are closing. Retrieved from http://www.usnews.com/news/blogs/data-mine/2015/03/16/federal-data-show-racial-gap-in-high-school-graduat ion-rates-is-closing

Burgstahler, S., Moore, E., \& Crawford, L. (2011). 2011 report of the Access STEM/Access Computing/DO-IT longitudinal transition study (ALTS). Seattle: University of Washington. http://www.washington.edu/doit/Stem/tracking4.html

Camara, W., \& Quenemoen, R. (2012). Defining and Measuring College and Career Readiness and Informing the Development of Performance Level Descriptors (PLDS). Paper Commissioned by the Partnership for Assessment of Readiness for College and Careers. Retrieved from http://www.parcconline.org/sites/parcc/files/PARCC\%20CCR\%20paper\%20v14\%201- 8- 12.pdf

Carnevale, A. P., Smith, N. \& Strohl, J. (2010). Help Wanted: Projections of jobs and education requirements through 2018. Georgetown University Center on Education and the Workforce. Retrieved from http://cew.georgetown.edu/jobs2018/

Casto, C. (2007). Building a Pathway to the U: The Adelante partnership helps underrepresented students see a future for themselves in higher education. Continuum Magazine. Retrieved from http://www.continuum.utah.edu/2007summer/feature3.html

Castro, E. L. (2012). Rethinking College and Career Readiness: A call for context to address racial inequality. Newsletter. Champaign, IL: Office of Community College Research and Leadership. Retrieved from http://occrl.illinois.edu/articles/rethinking-college-and-career-readiness-a-call-for-understanding-context-to-addr ess-racial-inequality/

Center on Instruction. (2008). A synopsis of Hattie \& Timperley's 'Power of feedback.' Portsmouth, NH: RMC Research Corporation: Author. Retrieved from http://centeroninstruction.org/files/Corrected\%20Synopsis\%20Power\%20of\%20Feedback.pdf

Charles, N. (2015). Culturally responsive instruction: Accelerating academics through student engagement. Retrieved from http://digitalcommons.georgiasouthern.edu/nyar_savannah/2015/2015/151/

Chau, J. (2012). AP test takers scores increase, but minority participation still lags. Retrieved from http://chronicle.com/article/AP-Test-TakersScores/130711/

Cobb, B., \& Alwell, M. (2007). Transition planning/coordinating interventions for youth with disabilities: A systematic review. National Secondary Transition Technical Assistance Center.

Gysbers, N. (2013). Career-ready students: A goal of comprehensive school counseling programs. The Career Development Quarterly, 61, 283-288. http://dx.doi.org/10.1002/j.2161-0045.2013.00057.x

Gysbers, N. C., \& Lapan, R. T. (2009). Strengths-based career development for school guidance and counseling programs. Chelsea, Ml: Counseling Outfitters.

Hammond, L., Friedlaender, D., \& Snyer, J. (2014). Student centered schools: Policy supports for closing the opportunity gap. Stanford Center for Opportunity Policy in Education. Retrieved from https://edpolicy.stanford.edu/sites/default/files/scope-pub-student- centered- policy.pdf

Hawkins, R., \& Mulkey, L.M. (2005). Athletic Investment and Academic Resilience in a National Sample of African American Females and Males in the Middle Grades. Education and Urban Society, 38, 62-88. 
http://dx.doi.org/10.1177/0013124505280025

Hogrebe, M. C., \& Tate, W. F., IV. (2010, April). School composition and context factors that moderate and predict 10th-grade science proficiency. Teachers College Record, 112(4), 1096-1136.

Holcomb-McCoy, C., \& Mitchell, N. (2005). A descriptive study of urban school counseling programs. Professional School Counseling, 8(3), 203-209.

Inver Hills Community College (2014). Definition of diversity. Retrieved from http://depts.inverhills.edu/paralegal/diversity-whatis.htm

Kearney, M. S., \& Levine, P.B. (2014). Income inequality, social mobility, and the decision to drop out of high school. National Bureau of Economic Research, Working Paper 20195, 1-34.

Lee, C. C., \& Wagner, A. M. (2007). Counseling in urban schools: Context, challenges, characteristics, and competencies. In J. Wittmer \& M.A. Clark, (Eds.), Managing your school program (pp. 267-274). Minneapolis, MM: Educational Media Corporation.

Lee, C. C. (2005). Urban school counseling: Context, challenges, characteristics, and competencies. Professional School Counseling, 8, 184-188. Retrieved from MasterFILE Premier database.

Maruyama, G. (2012). Assessing College Readiness: Should we be satisfied with ACT or other threshold scores? Educational Researcher, 41, 252-261. http://dx.doi.org/10.3102/0013189X12455095

National Center Education Statistics (NCES) (2013). Public school graduates and dropouts from the common core of data: School year 2009-2010. Retrieved from http://nces.ed.gov/pubs2013/2013309rev.pdf

National Education Association (NEA) (2011). Race against time: Educating black boys. Retrieved from http://www.nea.org/assets/docs/educatingblackboys11rev.pdf

National Office for School Counselor Advocacy (NOSCA) (2011). Urban school counseling initiative: Transforming school counseling district wide. Retrieved from http://www.docstoc.com/docs/152582938/NOSCA-s-Urban-School-Counseling- Initiative---College-Board

Newman, L., Wagner, M., Cameto, R., Knokey, A.-M., \& Shaver, D. (2010). Comparisons Across Time of the Outcomes of Youth With Disabilities up to 4 Years After High School A Report of Findings From the National Longitudinal Transition Study (NLTS) and the National Longitudinal Transition Study-2 (NLTS2) (NCSER 2010-3008). Menlo Park, CA: SRI International.

Olsen, L. (2010). A closer look at long-term English learners: A focus on new directions. In the Starlight, 7. Retrieved from http://en.elresearch.org/uploads/Olsen_Color_eng.pdf

Padrón, Y. N., Waxman, H. C., \& Rivera, H. H. (2002). Educating Hispanic students: Obstacles and avenues to improved academic achievement. Santa Cruz, CA: Center for Research on Education, Diversity \& Excellence. Retrieved from http://www.cal.org/crede/pdfs/epr8.pdf

Perna, L., Rowan-Kenyon, H., Thomas, S., Bell, A., Anderson, R., \& Li, C. (2008). The role of college counseling in shaping college opportunity: Variations across high schools. Review of Higher Education, 31(2), 131-159. http://dx.doi.org/10.1353/rhe.2007.0073

Research Engagement and Communities for Hispanic Educated Students (REACHES) (2014). Promising practices for engaging Hispanic/Latino students in georgia. Retrieved from http://www.gpee.org/fileadmin/files/PDFs/Promising_Practices_for_Engaging_HispanicLatino_Students_in_Ge orgia_February_2014_2_.pdf

Rumberger, R. (2006). Tenth grade dropout rates by native language, race/ethnicity, and socioeconomic status. Berkeley, CA: University of California, Berkeley, University of California Linguistic Minority Research Institute. Retrieved from http://escholarship.org/uc/item/2903c3p3

Sanford, C., Newman, L., Wagner, M., Cameto, R., Knokey, A.-M., \& Shaver, D. (2011). The Post- High School Outcomes of Young Adults With Disabilities up to 6 Years After High School. Key Findings From the National Longitudinal Transition Study-2 (NLTS2) (NCSER 2011-3004). Menlo Park, CA: SRI International.

Somers, C.L, Owens, D., \& Piliawsky, M. (2008). Individual and social-factors related to urban African American adolescents' school performance. The High School Journal, Feb/March 2008, 1-10. http://dx.doi.org/10.1353/hsj.2008.0004

Spatig-Amerikaner, A. (2012, August). Unequal Education: Federal loophole enables lower spending on students of 
color. Center for American Progress. Retrieved from http://www.americanprogress.org/wp-content/uploads/2012/08/UnequalEduation.pdf

Swanson, C. B. (2010). U.S. graduation rate continues decline. Retrieved from http://www.edweek.org/ew/articles/2010/06/10/34swanson.h29.html

The College Board (2014). Access to opportunity. Retrieved from http://professionals.collegeboard.com/guidance/access-to-opportunity

United States Department of Education, Office of Planning, Evaluation \& Policy. (2010). ESEA Blueprint for Reform. Washington, DC: Author. Retrieved from http://www2.ed.gov/policy/elsec/leg/blueprint/blueprint.pdf

United States Department of Justice, Office of Justice Programs, Bureau of Justice Statistics. (2011, December). Correctional Population in the United States, 2010. Retrieved from http://bjs.ojp.usdoj.gov/content/pub/pdf/cpus10.pdf

Wagner, M., Newman, L., Cameto, R., Levine, P., \& Garza, N. (2006). An Overview of Findings From Wave 2 of the National Longitudinal Transition Study-2 (NLTS2). (NCSER 2006-3004). Menlo Park, CA: SRI International.

Western, B., \& Pettit, B. (2010). Incarceration and social inequality. Daedalus, 139, 8-19. http://dx.doi.org/10.1162/DAED_a_00019

Zalaquett, C. (2004). Increasing school counselors impact on the achievements of Hispanic/latino students. Retrieved from http://www.ncda.org/aws/NCDA/pt/sd/news_article/4860/_PARENT/layout_details_cc/f alse 